\title{
Raiva em animais domésticos e silvestres no estado do Maranhão no período de 2013 a 2016: um estudo retrospectivo
}

Naylla Raquel Costa Leite Campos, Alcina Vieira de Carvalho Neta, Natalia Lustosa Cavalcante, Juliana da Silva Alves, Danilo Cutrim Bezerra, Amanda Taylla Lima Silva, Maria do Socorro C.O. Braga, Nancyleni Pinto Chaves Bezerra, Ferdinan Almeida Melo, Hamilton Pereira Santos

Universidade Estadual do Maranhão (UEMA), São Luís, MA, Brasil

*Autor correspondente

e-mail: hpsluiza@yahoo.com.br

\section{Resumo}

A raiva é uma das zoonoses de maior importância em saúde pública, em função da evolução invariavelmente fatal e pelo custo social e econômico que determina. A enfermidade é causada pelo vírus da raiva, pertencente ao gênero Lyssavirus, família Rhabdoviridae. A enfermidade é mantida e perpetuada na natureza por várias espécies animais, como carnívoros domésticos e silvestres, herbívoros e morcegos de diferentes hábitos alimentares. Nesse contexto potencialmente crítico, o trabalho foi estruturado com o objetivo de determinar a prevalência da raiva em animais domésticos e silvestres no estado do Maranhão, utilizando dados do Serviço de Defesa Agropecuária e da Vigilância Sanitária do Estado do Maranhão, no período de 2013 a 2016 . Foram utilizados os condensados estaduais dos informes mensais, FORM-INs, FORM-COMs, sobre a ocorrência e o diagnóstico clínico e laboratorial da raiva. As prevalências relativas foram calculadas por espécie animal. Foram avaliados 486 laudos laboratoriais de amostras provenientes de animais domésticos e silvestres, no período de levantamento dos dados. Deste total, 301 eram de cães, 90 de quirópteros, 64 de bovinos, 15 de felinos, oito de equinos, duas de ovinos, uma de asinino, uma de muar, uma de suíno, uma de raposa, uma de primata e uma de humano. No estudo, foi identificada prevalência de 13,17\% (64/486). As espécies positivas foram assim distribuídas: 26 (5,35\%) bovinos, 26 (5,35\%) caninos, quatro (0,82\%) equinos, três $(0,61 \%)$ felinos, um $(0,21 \%)$ muar, um $(0,21 \%)$ asinino, um $(0,21 \%)$ suíno, uma $(0,21 \%)$, raposa e um $(0,20 \%)$ quiróptero. Das espécies avaliadas, o maior percentual de casos positivos foi para as espécies bovina, canina e equina. Neste levantamento, foi possível a identificação da raiva ao longo de todos os anos de observação. Com bases nos documentos avaliados, os principais fatores que podem ter contribuído para a ocorrência de raiva nos animais domésticos e silvestres no estado do Maranhão foram: aumento da oferta de alimento, representado pelo significativo crescimento dos rebanhos; ocupação desordenada, caracterizada por macro modificações ambientais como desmatamento, construção de rodovias e hidroelétricas, que alteraram o 
ambiente em que os morcegos vivem, obrigando-os a procurar novas áreas e outras fontes de alimentação; oferta de abrigos artificiais, representados pelas construções como túneis, cisternas, casas abandonadas, bueiros, fornos de carvão desativados. Com base nos resultados obtidos, pode-se concluir que a prevalência de raiva no estado do Maranhão, no período avaliado, foi alta, e que as espécies bovina, canina e equina foram as mais acometidas em todos os períodos de avaliação. Considerando as condições econômicas de criação e produção no estado, bem como a ausência de planejamento amostral adequado, sugere-se que esforços sejam concentrados na intensificação da vacinação, captura de morcegos e educação em saúde. 